\title{
Características da silagem de cana-de-açúcar tratada com inoculante bacteriano e hidróxido de sódio e acrescida de resíduo da colheita de soja ${ }^{1}$
}

\author{
Acyr Wanderley de Paula Freitas ${ }^{2}$, José Carlos Pereira ${ }^{3}$, Fernanda Cipriano Rocha ${ }^{4}$, Edenio \\ Detmann ${ }^{3}$, Marinaldo Divino Ribeiro ${ }^{5}$, Marcone Geraldo Costa ${ }^{5}$, Fernando de Paula Leonel ${ }^{5}$
}

${ }^{1}$ Parte da tese de Doutorado em Zootecnia do primeiro autor.

2 Instituto de Zootecnia.

${ }^{3}$ Departamento de Zootecnia-UFV.

${ }^{4}$ Doutora em Zootecnia - UFV.

${ }^{5}$ Pós-Graduação em Zootecnia - UFV.

RESUMO - Objetivou-se neste trabalho avaliar a qualidade nutricional e as características fermentativas da silagem de cana-de-açúcar tratada com inoculante microbiano (Lactobacillus plantarum nas doses 1,0; 1,2 e $1,4 \times 10^{6} \mathrm{ufc} / \mathrm{g} \mathrm{MN}$ ) e hidróxido de sódio (solução $40 \%$ na base de 3\% da MS) e acrescida de $10 \%$ de resíduo da colheita de soja, com base no peso verde da cana. Foi utilizada a variedade RB855536, colhida em soca aos 11 e 13 meses. O experimento foi conduzido em delineamento inteiramente ao acaso, com três repetições, em esquema fatorial 2 × 8 (duas idades e oito tratamentos da massa ensilada). Os resultados foram avaliados pela análise de fatores. Para as variáveis de composição e cinética de degradação, foram obtidos três fatores: QN - qualidade nutritiva, incluindo MS, PB, DIVMS, FDN, FDA e LIG; MF - maturidade fisiológica, incluindo carboidratos solúveis, LIG e fração indegradável da FDN; e VDF - velocidade de degradação dos carboidratos fibrosos, contemplando o $\mathrm{kd}_{\mathrm{FDN}}$. Às variáveis de características de fermentação atribuíram-se os fatores: PFS - perdas e fermentação secundária, incluindo perda de MS, concentração de ácido acético, ácido propiônico e etanol; PH - potencial hidrogeniônico, pH; e DP - degradação protéica, concentração de nitrogênio amoniacal. O resíduo da colheita da soja na ensilagem da canade-açúcar foi capaz de melhorar a qualidade nutritiva e reduzir as perdas de MS e a produção de etanol das silagens. O tratamento com hidróxido de sódio diminuiu a produção de etanol, mas não melhorou a qualidade nutritiva e não reduziu as perdas de MS das silagens. A utilização de inoculante microbiano contendo L. plantarum também não melhorou a qualidade nutritiva da silagem nem reduziu as perdas de MS e a produção de etanol.

Palavras-chave: ensilagem, fibra, parâmetros fermentativos, perda de matéria seca

\section{Characteristics of sugarcane silage treated with bacterial inoculant, sodium hydroxide or soybean crop residue}

\begin{abstract}
The objective of this trial was to evaluate the nutritional quality and fermentation characteristics of sugarcane silages treated with inoculant (Lactobacillus plantarum in doses of $1.0,1.2$ and $1.4 \times 10^{6} \mathrm{cfu} / \mathrm{g} \mathrm{NM}$ ), $40 \%$ sodium hydroxide solution ( $3 \%$ dry matter basis), or $10 \%$ of soybean crop residue added according to the sugarcane fresh weight. The variety RB855536 harvested at 11 and 13 months of age was used. The experiment was conducted at the Universidade Federal de Viçosa Animal Science Department, Viçosa, MG, in a completely randomized design (three repetitions per treatment) with a factorial arrangement of $2 \times 8$ (two ages and eight treatments). For evaluation of chemical composition and degradation kinetic of silages three parameters were considered: 1) "nutritional quality" that included contents of dry matter, crude protein, neutral detergent fiber, acid detergent fiber, lignin and in vitro dry matter digestibility; 2) "physiological maturity" that included soluble carbohydrates, lignin, and the neutral detergent fiber undegradable fraction; and 3) "degradation velocity of fiber carbohydrates" that included $\mathrm{kd}_{\mathrm{NDF}}$. For evaluation of fermentation characteristics the following parameters were adopted: 1) "secondary fermentation and losses" that included DM losses, acetic acid, propionic acid, and ethanol concentrations; 2) "hydrogen potential" ( $\mathrm{pH}$ ); and 3) "protein degradation" (PD) that included ammonia-N concentration. Soy crop residue improved silage nutritional quality and reduced both DM losses and ethanol production. Treatment with sodium hydroxide also decreased ethanol production but did not improve nutritional quality and was not able to prevent DM losses. Use of L. plantarum did not improve the nutritional quality of silages or reduced their DM losses and ethanol production.
\end{abstract}

Key Words: dry matter loss, ensilage, fermentative parameters, fiber 


\section{Introdução}

A cana-de-açúcar (Saccharum spp.) constitui uma alternativa de alimento volumoso para alimentação de bovinos durante o período da seca. Neste período, em razão da escassez das chuvas e da baixa qualidade das forrageiras, seu uso em associação principalmente à uréia fornece energia, fibra e proteína aos animais a custo mais baixo que o de outras alternativas de suplementação, como silagem de milho ou de sorgo, em decorrência de sua alta produtividade por área.

A cana-de-açúcar oferecida in natura, mediante cortes diários, apresenta alguns inconvenientes, como a contratação de mão-de-obra diária para cortes, despalhamento, desintegração e transporte. Por isso, muitos produtores têm optado pela ensilagem como alternativa de utilização desta forrageira, principalmente em situações em que é usada como forragem durante todo o ano, pela perda do valor nutritivo durante o verão, decorrente do baixo teor de sacarose (Matsuoka \& Hoffmann, 1993), e pela dificuldade de colheita em dias de chuva.

Apesar do crescente número de produtores adeptos à ensilagem da cana-de-açúcar, ainda são escassas informações sobre a qualidade destas silagens submetidas a diferentes tratamentos. Informações recentes (Nussio et al., 2003; Pedroso, 2003) indicam que a ensilagem da cana é uma prática que facilita seu manejo em sistemas de produção, por melhorar a eficiência de colheita, pois permite o aproveitamento de talhões em declínio (em rendimento, em acamamento ou prejudicados por geadas ou fogo), além de disponibilizar o material em outros períodos de escassez de alimento.

A conservação da cana por meio da ensilagem, além de proporcionar homogeneização do material ensilado, apresenta boa economicidade, uma vez que o corte e a desintegração diários desta forragem exigem mão-de-obra adicional. Outro aspecto a ser considerado é a liberação da área para rebrotação homogênea das plantas, proporcionando melhor cobertura do solo e maior índice de área foliar para o período das águas e, conseqüentemente, menores gastos com o controle de plantas invasoras.

Por outro lado, o inconveniente desta forrageira na obtenção de silagem é seu alto conteúdo de açúcares solúveis, que resulta em rápida proliferação de leveduras com produção de etanol e gás carbônico (Valvasori et al., 1995). Em condições aeróbicas, as leveduras são capazes de sobreviver com diversos ácidos orgânicos por tempo maior que a maioria dos microrganismos. Em condições anaeróbicas, no entanto, as leveduras precisam obter sua energia da fermentação de açúcares (McDonald et al., 1991).
Essa intensa atividade das leveduras provoca redução de até $44 \%$ no teor de carboidratos solúveis e aumento no teor de componentes da parede celular e nas perdas de matéria seca (Alli et al., 1983). Teores de etanol de 7,8 a 17,5\% da MS têm sido observados em silagem de cana-de-açúcar isolada, resultando em perdas de até $29 \%$ da MS da silagem (Kung Jr. \& Stanley, 1982; Andrade et al., 2001; Silva, 2003).

Para melhorar a eficiência do processo de fermentação, existe uma variedade de aditivos para silagem. A adição de um produto com alto teor de MS funciona como um aditivo absorvente, elevando o teor de MS do material ensilado, o que torna o ambiente menos favorável para o desenvolvimento das leveduras. A utilização de aditivos microbianos contendo bactérias acido-láticas promove queda mais acentuada do $\mathrm{pH}$ da silagem e rápido acúmulo de ácido-lático. Apesar de o crescimento de leveduras não ser inibido pelos baixos níveis de $\mathrm{pH}$ durante o processo de ensilagem (McDonald et al., 1991), o aumento da população inicial de bactérias acido-láticas aumenta a competição por substrato entre os microrganismos, inibindo o desenvolvimento das leveduras em condições anaeróbicas.

Para obtenção de silagens com bom padrão de fermentação, o teor de MS do material a ser ensilado é muito importante. Andrade et al. (2001) observaram redução na produção de etanol à medida que níveis mais altos de rolão-de-milho foram utilizados na ensilagem, demonstrando que o aumento do teor de MS diminui a produção de etanol.

Outra alternativa seria empregar o resíduo da colheita da soja, constituído de grãos quebrados e pequenos, vagens, hastes e folhas, de modo que os grãos contribuem com, aproximadamente, $50 \%$ da sua composição, conferindo elevado valor nutritivo à silagem. Portanto, além de aumentar o teor de MS do material a ser ensilado, o resíduo da colheita de soja pode aumentar o valor nutritivo da silagem.

Alcântara et al. (1989) estudaram o efeito da adição de hidróxido de sódio $(\mathrm{NaOH})$ na ensilagem da cana-de-açúcar e observaram melhoria no padrão de fermentação das silagens, com redução da produção de etanol, indicando que substâncias alcalinizantes também são capazes de modificar o processo fermentativo de silagens. Estas substâncias provavelmente exercem efeito germicida, diminuindo a população inicial de leveduras.

A idade da planta é um dos fatores que mais interferem na qualidade da cana-de-açúcar como alimento para bovinos. Quanto maior o grau de maturidade, menor o teor de fibra em detergente neutro (FDN), maiores os teores de açúcar e de MS e, portanto, melhor o seu valor para alimentação animal, pois a fibra apresenta baixa digestibilidade e os açúcares podem ser considerados totalmente digestíveis. 
No entanto, quanto mais alto o teor de açúcares, mais favorável o ambiente para a proliferação de leveduras durante o processo de ensilagem. Por outro lado, o maior teor de MS do material pode reduzir a proliferação destes microrganismos, pela elevação da pressão osmótica (Van Soest, 1994).

Considerando essas informações, avaliaram-se as características da silagem de cana-de-açúcar colhida em dois estádios de maturidade, tratada com inoculante microbiano e hidróxido de sódio e acrescida de resíduo da colheita da soja.

\section{Material e Métodos}

Oexperimento foi conduzido no Departamento deZootecnia da Universidade Federal de Viçosa (UFV), Viçosa-MG, onde foram realizados as coletas e o armazenamento das amostras. A variedade de cana-de-açúcar utilizada foi a RB855536, fornecida pelo Departamento de Fitotecnia e colhida nas dependências da UFV.

O município de Viçosa situa-se na Zona da Mata Mineira, a uma altitude média de $650 \mathrm{~m}$. O tipo climático é Cwa, segundo classificação de Köeppen, a umidade relativa média do ar, de $64,7 \%$, e a precipitação pluviométrica média anual, de $1.431 \mathrm{~mm}$, dos quais $85 \%$ ocorrem entre outubro e março. As médias de temperatura máximas e mínimas são, respectivamente, 26,1 e $14,0^{\circ} \mathrm{C}$, conforme dados fornecidos pelo Serviço de Meteorologia do Departamento de Engenharia Agrícola da UFV.

Os cortes e as ensilagens foram realizados em maio e julho de 2003, quando o material possuía 11 e 13 meses, respectivamente.

O resíduo da colheita da soja foi adicionado à cana-deaçúcar recém-picada no nível de 10\%, com base na matéria natural. Nos tratamentos com hidróxido de sódio, foi utilizada uma solução de $40 \%$ e adicionada na base de $3 \%$ do peso seco do material. O inoculante microbiano utilizado foi o Lactobacillus plantarum, na dose recomendada para silagem de milho $\left(1,0 \times 10^{6} \mathrm{ufc} / \mathrm{g}\right.$, na matéria natural $)$ e em doses 20 e $40 \%$ superiores ( 1,2 x $10^{6} \mathrm{ufc} / \mathrm{g}$ de $\mathrm{MN}$ e $1,4 \mathrm{x}$ $10^{6} \mathrm{ufc} / \mathrm{g}$ de $\left.\mathrm{MN}\right)$, aplicadas por aspersão.

Dessa forma, foram constituídos oito tratamentos: 1 - controle; 2 - L. plantarum $1,0 \times 10^{6} \mathrm{ufc} / \mathrm{g}$ de $\mathrm{MN}$; 3 - L. plantarum $1,2 \times 10^{6} \mathrm{ufc} / \mathrm{g}$ de $\mathrm{MN} ; 4$ - L. plantarum 1,4 x $10^{6}$ ufc/g de MN; 5 - resíduo; $6-\mathrm{NaOH} ; 7$ - resíduo + $\mathrm{NaOH} ; 8$-resíduo + L. plantarum $1,0 \times 10^{6} \mathrm{ufc} / \mathrm{g}$ de $\mathrm{MN}$.

A cana-de-açúcar foi colhida por corte manual e desintegrada em ensiladora estacionária, regulada para cortar a forragem em pedaços de aproximadamente $2 \mathrm{~cm}$ de comprimento.
O material foi ensilado em silos experimentais feitos com canos de PVC (0,75 m de altura e $0,25 \mathrm{~m}$ de diâmetro), dispostos em bancadas de madeira e mantidos em local coberto, em temperatura ambiente, até o momento da abertura. Na parte inferior dos silos, havia um cano de PVC de 1/2" de diâmetro, fechado com tampa rosqueável, para escoamento e coleta do efluente produzido. Em cada silo, foram colocados $10 \mathrm{~kg}$ da mistura fresca até a altura de $37 \mathrm{~cm}$, de modo a obter a densidade de $550 \mathrm{~kg} / \mathrm{m}^{3}$. A compactação foi realizada manualmente com êmbolo de madeira e o fechamento com tampas de madeira lacradas com fita adesiva e sacos plásticos.

Para avaliação das perdas, os silos experimentais foram pesados antes da ensilagem, logo após a ensilagem e ao final do período de armazenamento, para que fosse possível o cálculo do peso líquido da forragem contida em cada silo, no início e no final do experimento.

Após 45 dias de armazenamento, os silos foram abertos e todo o seu conteúdo foi retirado e colocado sobre uma lona plástica para homogeneização. Após esse procedimento, foram retiradas amostras de cada unidade experimental, sendo separada uma amostra para extração do suco utilizando-se prensa hidráulica. No suco das silagens, que foi mantido congelado em freezer, foram determinados os teores dos ácidos acético, propiônico, butírico e lático e a concentração de etanol. Foram estimadas também a concentração de nitrogênio amoniacal $\left(\mathrm{N}_{-} \mathrm{NH}_{3}\right)$, expressa como porcentagem do nitrogênio total, e o potencial hidrogeniônico $(\mathrm{pH})$, com potenciômetro digital (Bolsen et al., 1992).

Uma segunda amostra foi pesada, acondicionada em sacos de papel e colocada em estufa de ventilação forçada a $60^{\circ} \mathrm{C}$ por 72 horas. Em seguida, as amostras foram retiradas da estufa, mantidas à temperatura ambiente por uma hora $\mathrm{e}$ pesadas para determinação da matéria pré-seca. Posteriormente, as amostras foram trituradas em moinho tipo "Willey" com peneira de malha de $1 \mathrm{~mm}$ e acondicionadas em vidros com tampa para posteriores análises.

Os valores de MS, PB, FDN, FDA, LIG, HEM, carboidratos solúveis (CS) e DIVMS foram determinados conforme técnica descrita por Silva \& Queiroz (2002) e o nitrogênio insolúvel em detergente ácido (NIDA), de acordo com método descrito por Licitra et al. (1996). As concentrações de ácido láctico, ácidos graxos voláteis e álcool etílico foram determinadas por cromatografia líquida de alta performance (HPLC). A fase móvel utilizada foi o $\mathrm{H}_{2} \mathrm{SO}_{4}$ $\left(0,005 \mathrm{~mol} \mathrm{~L}^{-1}\right)$ a uma taxa de fluxo de $0,6 \mathrm{~mL}$ por minuto, $\mathrm{a} 40^{\circ} \mathrm{C}$ (AOAC, 1990).

As taxas de digestão da FDN foram estimadas pela técnica de produção cumulativa de gases. Aproximadamente 
$100 \mathrm{mg}$ de amostras da fibra insolúvel em detergente neutro, moídas em peneiras com crivos de $1 \mathrm{~mm}$, foram incubados em triplicata, em frascos de vidro de $50 \mathrm{~mL}$ contendo $8 \mathrm{~mL}$ da solução tampão de McDougall (McDougall, 1949), previamente reduzida com $\mathrm{CO}_{2}(\mathrm{pH} 6,9-7,0)$ e $2 \mathrm{~mL}$ de inóculo ruminal proveniente de dois bovinos fistulados no rúmen. Seqüencialmente, os frascos receberam tampa de borracha e lacre de alumínio e permaneceram em mesa de agitação orbital (44 rpm) em uma sala climatizada, mantida a $39^{\circ} \mathrm{C}$. As leituras de pressão foram realizadas por meio de um sensor de pressão acoplado a um voltímetro, nos seguintes tempos: $1,2,3,4,5,6,9,12,18,24,30,36,48,60,72,96$ e 120 horas (Maurício et al., 1999). As leituras realizadas em volts foram convertidas para mL conforme Pell \& Schofield (1993). A cinética da produção cumulativa dos gases foi analisada empregando-se o modelo de regressão não-linear de Brody:

$$
V(t)=V f\left[1-b^{(-\mathrm{c} * t)}\right]
$$

Neste modelo $V(t)$ é o volume de gases acumulado $(\mathrm{mL})$ no tempo " $t$ "; $V f$, o volume total de gás produzido em “t” $(\mathrm{mL}) ; \mathrm{c}$, a taxa específica de produção de gases; $b$, parâmetro de forma, sem interpretação biológica; e t, o tempo de incubação.

Os resultados dos parâmetros de fermentação foram separados dos de composição química e cinética de degradação para execução das análises estatísticas.

O delineamento experimental foi o inteiramente ao acaso, com três repetições em esquema fatorial 2 × 8 (duas idades e oito tratamentos da massa ensilada).

Após a avaliação das variáveis, os resultados foram reduzidos às médias dos tratamentos, sendo analisados por meio da análise de fatores ("factor analysis"), empregando-se o método "Varimax" de rotação e ortogonalização dos fatores, adotando-se como critério de seleção dos fatores as cargas fatoriais e a fração retida na variação total comunalidade (Johnson \& Wichern, 1998). As análises estatísticas foram realizadas utilizando-se o programa SAS, versão 8.0 (UFV, 1998).

\section{Resultados e Discussão}

A composição bromatológica da cana-de-açúcar, nos dois estádios de maturidade, e do resíduo da colheita da soja encontram-se na Tabela 1. A cana-de-açúcar utilizada para ensilagem apresentou teores médios de MS, teores elevados de DIVMS (nos dois estádios de maturidade) e dos componentes da fração fibrosa (aos 11 meses de idade) e teores baixos destes componentes aos 13 meses de idade, se comparados aos valores observados por Azevêdo et al. (2003) e Rodrigues et al. (2001a), ao avaliarem variedades industriais colhidas aos 12 e 13 meses de idade, respectivamente. Esses autores encontraram valores variando de: 23,1 a $28,7 \%$ de MS; 43, 8 a 53,8\% deFDN; 24,3 a 29,7\% de FDA; 12,1 a $17,1 \%$ (\% FDN) de lignina; e 58,3 a 69,0\% de DIVMS.

A redução nos teores de FDN e de FDA da primeira para a segunda época de colheita é normalmente verificada para cana-de-açúcar, contrariamente ao observado para as demais espécies forrageiras. Esse declínio pode ser explicado pela "diluição" dos constituintes da parede celular vegetal, com expressivo aumento do teor de carboidratos solúveis (CS),

Tabela 1 - Composição bromatológica e digestibilidade in vitro da matéria seca (DIVMS) da cana-de-açúcar e do resíduo da colheita de soja utilizados na ensilagem

Table 1 - Chemical composition and "in vitro" dry matter digestibility (IVDMD) of sugarcane and soy crop residue used for ensilage

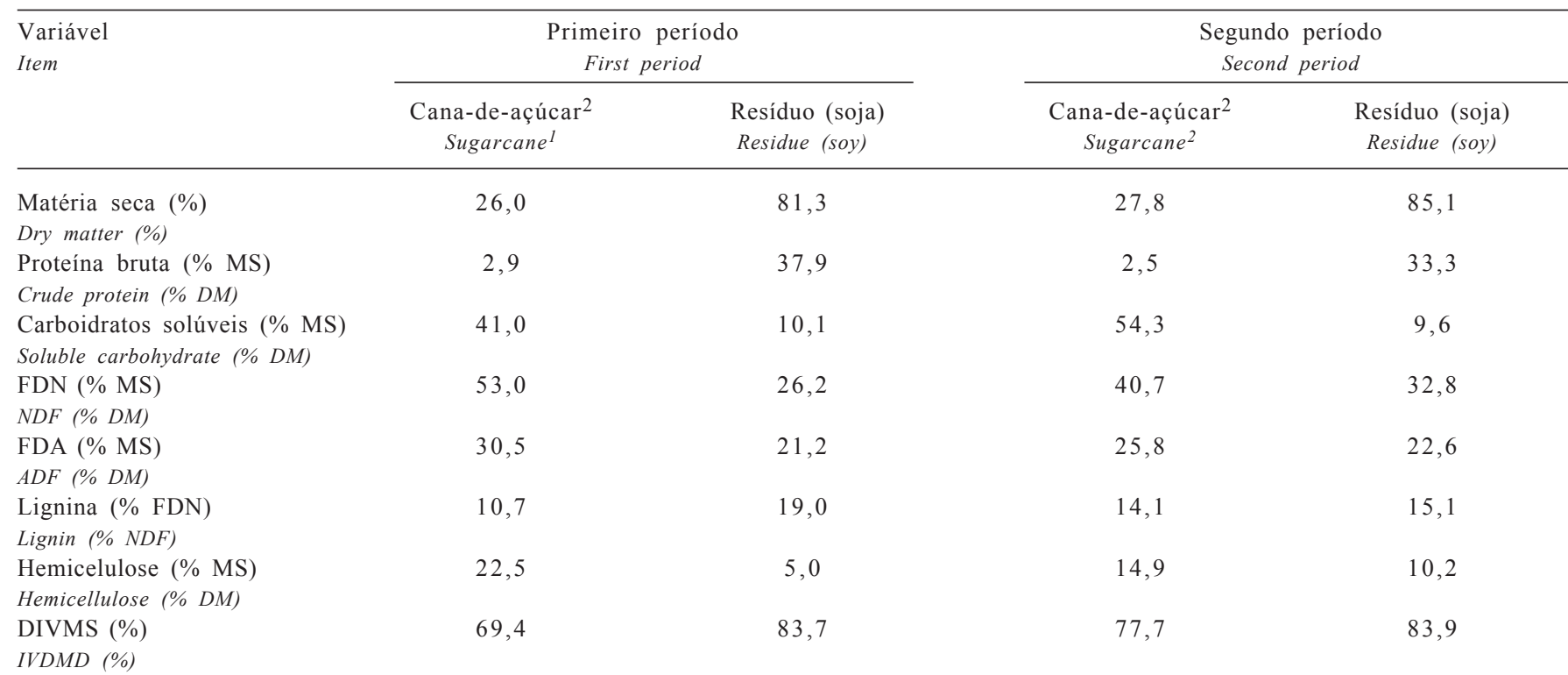

111 meses; 213 meses.

111 months; ${ }^{2} 13$ months. 
de $41 \%$ no primeiro período para $54,3 \%$ no segundo (Tabela 1), sendo o mesmo comportamento observado por Carvalho (1992), em estudo de cinco variedades de cana-de-açúcar, nas quais o teor de FDN apresentou maior concentração na MS próximo aos 241 dias de crescimento, reduzindo deste ponto em diante.

Os teores de CS verificados para a cana-de-açúcar nos dois períodos podem ser considerados elevados, se comparados aos relatados nos trabalhos de Pedroso (2003), em torno de 23\%. Entretanto, Alli \& Baker (1982), em estudo com cana-de-açúcar colhida aos 7,5 meses de crescimento, relataram valor intermediário ( $52 \%$ de CS na MS) aos verificados para as duas idades de corte neste trabalho.

Não foi observada produção de efluente nas silagens durante o período de armazenamento para as duas idades avaliadas.

Na Tabela 2 são apresentados os resultados médios da composição química, da DIVMS e das estimativas das taxas de degradação da fração de carboidratos fibrosos das silagens estudadas.

A variação dos dados foi explicada em $92,98 \%$ por apenas três fatores (Tabela 3 ), com $58,33 \%$ para o primeiro, $26,6 \%$ para o segundo e $8,05 \%$ para o terceiro fator, destacando-se as elevadas comunalidades para cada uma das variáveis avaliadas (maioria acima de $90 \%$ ), exceto a fração indegradável da FDN $(I)(70,99 \%)$, demonstrando que grande parte da variação para essa variável (aproximadamente $29 \%$ ) seria de origem aleatória.
O fator 1 correlacionou-se fortemente, de forma positiva, com as variáveis $\mathrm{MS}(0,9335), \mathrm{PB}(0,9588)$ e $\operatorname{DIVMS}(0,9126)$. Além disso, foi observada correlação negativa com as variáveis FDN (-0,8171), FDA (-0,9079) e LIG (-0,66406), indicando que os aumentos nos escores fatoriais para o fator 1 denotam melhoria na composição química da forragem, com aumentos nos teores de $\mathrm{PB}$ e na digestibilidade e redução dos carboidratos fibrosos. Portanto, convencionou-se que esse fator reflete a "qualidade nutricional" (fator QN).

As fortes correlações positivas do fator 2 (Tabela 3 ) com as variáveis CS $(0,9283)$, LIG $(0,6844)$ e com a fração indegradável da FDN (I) $(0,8177)$ demonstraram que esse fator está associado à "maturidade fisiológica" (fator MF) da cana-de-açúcar.

O fator 3, pela sua elevada correlação com as taxas de degradação da FDN (Tabela 3), foi denominado fator de "velocidade de degradação dos carboidratos fibrosos" (fator VDF).

Foram observados escores fatoriais positivos do fator QN (Tabela 4) somente para as silagens com adição do resíduo da colheita de soja, independentemente da idade da cana-de-açúcar utilizada para ensilagem.

Os tratamentos somente com inoculante microbiano apresentaram escores fatoriais negativos e próximos aos das silagens controle (Figura 1), indicando que estes tratamentos não foram eficientes em melhorar a qualidade nutritiva das silagens. O tratamento em que se adicionou somente o hidróxido apresentou escores fatoriais superiores

Tabela 2 - Resultados médios para teores de MS, PB, CS, DIVMS, FDN, FDA, LIG, fração indegradável da FDN $(I)$ e taxa de degradação da FDN $\left(k_{F D N}\right)$ das silagens

Table 2 - Mean DM, CP, SC, IVDMD, NDF, ADF, LIG, undegradable NDF fraction (I), and NDF degradation rate (kd $\left.{ }_{N D F}\right)$ of silages

\begin{tabular}{|c|c|c|c|c|c|c|c|c|c|c|}
\hline $\begin{array}{l}\text { Meses } \\
\text { Months }\end{array}$ & $\begin{array}{c}\text { Tratamento } \\
\text { Treatment }\end{array}$ & $\begin{array}{c}\text { MS (\%) } \\
D M(\%)\end{array}$ & $\begin{array}{l}\mathrm{PB}^{2} \\
C P^{2}\end{array}$ & $\begin{array}{l}\mathrm{CS}^{2} \\
S C^{2}\end{array}$ & $\begin{array}{c}\text { DIVMS (\%) } \\
I V D M D(\%)\end{array}$ & $\begin{array}{c}\mathrm{FDN}^{2} \\
N D F^{2}\end{array}$ & $\begin{array}{c}\mathrm{FDA}^{2} \\
A D F^{2}\end{array}$ & $\mathrm{Lig}^{2}$ & $\mathrm{I}(\%)$ & $\begin{array}{c}\mathrm{kd}_{\mathrm{FDN}} \\
k d_{N D F}\end{array}$ \\
\hline & Controle (Control) & 22,4 & 3,7 & 9,1 & 53,6 & 66,3 & 38,7 & 8,0 & 56,9 & 0,0259 \\
\hline & L. plantarum $1,0 \times 10^{6} \mathrm{ufc} / \mathrm{g}^{1}$ & 20,5 & 4,2 & 7,5 & 53,2 & 69,7 & 40,5 & 7,8 & 56,7 & 0,0201 \\
\hline & L. plantarum $1,2 \times 10^{6} \mathrm{ufc} / \mathrm{g}^{1}$ & 21,1 & 4,3 & 9,2 & 53,6 & 67,2 & 39,6 & 8,1 & 56,0 & 0,0210 \\
\hline & L. plantarum $1,4 \times 10^{6} \mathrm{ufc} / \mathrm{g}^{1}$ & 21,2 & 3,9 & 8,9 & 56,1 & 67,2 & 39,6 & 8,1 & 59,2 & 0,0188 \\
\hline \multirow[t]{9}{*}{11} & Resíduo da colheita da soja (R.soja) & & & & & & & & & \\
\hline & Soy crop residue (R.soy) & 29,2 & 10,2 & 10,9 & 67,0 & 54,4 & 33,0 & 5,3 & 55,1 & 0,0229 \\
\hline & $\mathrm{NaOH}$ & 20,2 & 4,1 & 9,3 & 60,4 & 66,3 & 40,4 & 8,1 & 55,7 & 0,0189 \\
\hline & R.soja (R.soy) $+\mathrm{NaOH}$ & 27,7 & 12,4 & 7,2 & 71,4 & 52,9 & 31,7 & 4,9 & 56,6 & 0,0205 \\
\hline & R.soja (R.soy)+L. plantarum $1,0 \times 10^{6}$ & 28,2 & 11,1 & 10,9 & 70,3 & 54,0 & 31,2 & 4,8 & 56,9 & 0,0224 \\
\hline & Controle (Control) & 20,7 & 3,9 & 17,6 & 59,1 & 61,2 & 39,3 & 9,0 & 62,1 & 0,0192 \\
\hline & L. plantarum $1,0 \times 10^{6} \mathrm{ufc} / \mathrm{g}^{1}$ & 20,4 & 3,9 & 18,3 & 60,3 & 59,1 & 38,2 & 9,2 & 56,6 & 0,0192 \\
\hline & L. plantarum $1,2 \times 10^{6} \mathrm{ufc} / \mathrm{g}^{1}$ & 21,6 & 4,0 & 20,2 & 63,6 & 57,0 & 35,5 & 8,0 & 53,9 & 0,0215 \\
\hline & L. plantarum $1,4 \times 10^{6} \mathrm{ufc} / \mathrm{g}^{1}$ & 21,8 & 3,5 & 22,5 & 63,9 & 55,4 & 36,6 & 9,7 & 62,0 & 0,0258 \\
\hline \multirow[t]{6}{*}{13} & Resíduo da colheita da soja (R.soja) & & & & & & & & & \\
\hline & Soy crop residue (R.soy) & 30,3 & 10,8 & 19,5 & 74,9 & 44,5 & 28,8 & 7,8 & 58,0 & 0,0236 \\
\hline & $\mathrm{NaOH}$ & 22,1 & 3,4 & 24,9 & 68,0 & 50,4 & 32,5 & 8,7 & 66,1 & 0,0217 \\
\hline & R.soja (R.soy) $+\mathrm{NaOH}$ & 30,2 & 11,4 & 21,0 & 74,5 & 43,3 & 27,8 & 7,8 & 66,3 & 0,0244 \\
\hline & R.soja (R.soy) + L. plantarum $1,0 \times 10^{6}$ & 29,5 & 9,9 & 20,0 & 72,9 & 45,4 & 28,2 & 8,3 & 63,4 & 0,0242 \\
\hline & $\mathrm{CV}(\%)$ & 2,66 & 6,59 & 12,49 & 2,59 & 2,76 & 3,11 & 10,20 & 2,05 & 14,35 \\
\hline
\end{tabular}

\footnotetext{
${ }^{1}$ Unidades formadoras de colônia por grama de matéria natural (colony forming units per gram of natural matter).

$2 \%$ da MS (\% of DM).
} 
Tabela 3 - Cargas fatoriais, comunalidade de cada variável e porcentagem da variância total correspondente a cada fator, após a rotação pelo método "Varimax", na análise fatorial

Table 3 - Rotated factor pattern, communality, and total variance percentage, corresponding to each factor, after rotation by the factorial analysis "Varimax" method

\begin{tabular}{|c|c|c|c|c|}
\hline \multirow[t]{2}{*}{$\begin{array}{l}\text { Variável } \\
\text { Item }\end{array}$} & \multicolumn{3}{|c|}{$\begin{array}{c}\text { Carga fatorial } \\
\text { Rotated factor pattern }\end{array}$} & \multirow[t]{2}{*}{$\begin{array}{c}\text { Comunalidade (\%) } \\
\text { Communality (\%) }\end{array}$} \\
\hline & $\begin{array}{l}\text { Fator } 1 \\
\text { Factor } 1\end{array}$ & $\begin{array}{l}\text { Fator } 2 \\
\text { Factor } 2\end{array}$ & $\begin{array}{l}\text { Fator } 3 \\
\text { Factor } 3\end{array}$ & \\
\hline $\mathrm{MS}(D M)$ & 0,93348 & $-0,01528$ & 0,30095 & 96,21 \\
\hline $\mathrm{PB}(C P)$ & 0,95879 & $-0,18470$ & 0,10311 & 96,40 \\
\hline $\mathrm{CS}(S C)$ & 0,13334 & 0,92825 & 0,14898 & 90,16 \\
\hline FDA $(A D F)$ & $-0,90791$ & $-0,30933$ & $-0,24528$ & 98,01 \\
\hline Lig & $-0,66406$ & 0,68438 & 0,04794 & 91,17 \\
\hline I & 0,17735 & 0,81772 & 0,09882 & 70,99 \\
\hline $\mathrm{kd}_{\mathrm{FDN}}\left(k d_{N D F}\right)$ & 0,25928 & 0,19737 & 0,94342 & 99,62 \\
\hline $\begin{array}{l}\% \text { da variância explicada pelos fatores } \\
\% \text { of variance explained by the factors }\end{array}$ & 58,33 & 26,60 & 8,05 & 92,98 \\
\hline
\end{tabular}

ao tratamento controle, mas ainda próximos, demonstrando que este tratamento promoveu pequena melhoria da qualidade nutritiva da silagem, evidenciada pelos menores teores de FDN e maiores valores de DIVMS (Tabela 2).

A melhoria da qualidade nutritiva das silagens com a adição do resíduo era esperada, pois este ingrediente apresenta elevados teores de MS e PB, alta digestibilidade e baixos teores de FDN e FDA em relação à cana-de-açúcar. No entanto, quando comparados o material original (Tabela 1) e as silagens (Tabela 2), houve redução de 4,6 a 7,1 pontos percentuais no teor de MS para as silagens de cana-deaçúcar pura ou com os aditivos microbianos, ao passo que as silagens com inclusão do resíduo, isoladamente ou em conjunto com os aditivos microbiano ou químico, apresentaram redução de 3,3 a 3,5 pontos percentuais.

Estes valores estão abaixo da variação verificada em trabalhos recentes com silagem de cana-de-açúcar sem a utilização de aditivos, nas quais foram observadas reduções de 4 a 9 pontos percentuais na MS das silagens em comparação ao material original (Andrade et al., 2001; Coan et al., 2002; Pedroso, 2003).

A redução no teor de MS da silagem controle manteve-se em torno de 19,5\%, estando, portanto, nos níveis encontrados na literatura, que variam de 19 a $31 \%$ (Alli et al., 1982; Kung Jr. \& Stanley, 1982; Coan et al., 2002).

Ao contrário do observado em silagens de cana-deaçúcar, os teores de MS das silagens de híbridos de sorgo, das silagens de girassol e das silagens de milho são iguais ou superiores ao do respectivo material ensilado (Pesce et al., 2000; Neumann et al., 2002; Rodrigues et al., 2001b; Rodrigues et al., 2004). De acordo com Van Soest (1994), o acréscimo no teor de MS ocorre principalmente pela forma- ção e perda de efluentes na fase fermentativa da massa ensilada. No entanto, nas silagens de cana-de-açúcar, a perda de efluente é muito pequena ou até inexistente; com isso, a "água metabólica" resultante dos processos de fermentação fica retida no material ensilado, contribuindo, conseqüentemente, para redução no teor de MS da forragem.

Segundo Rotz \& Muck (1994), em condições reais, a mudança nos níveis de FDN nas silagens pode variar de $-1 \%$ a $+4 \%$, com base na MS, dependendo das perdas por respiração em relação à quantidade de parede celular hidrolisada. Contudo, em silagens bem manejadas, a FDA se altera pouco. Sua concentração normalmente aumenta de 2 a 5\% na MS, como conseqüência da perda de outros carboidratos. Como o teor de CS na cana-de-açúcar é muito superior ao das forragens tradicionalmente utilizadas para ensilagem e avaliadas por estes autores, pode-se assumir que a concentração dos constituintes da parede celular na MS durante o processo de ensilagem da cana-de-açúcar deve ser maior.

Os acréscimos nos teores de FDN e FDA das silagens estão de acordo com as variações de 13 a 30\% e 14 a 44\%, respectivamente, verificadas na literatura (Alli \& Baker, 1982; Coan et al., 2002; Pedroso, 2003). Os menores valores de FDN e FDA obervados nas silagens com adição do resíduo (Tabela 2) podem ser atribuídos não somente aos menores teores destes componentes no resíduo, como citado anteriormente, mas também à menor redução nos teores de MS.

Maiores escores fatoriais para o fator QN observados para as silagens tratadas com $\mathrm{NaOH}$ (Tabela 4; Figura 1) resultam dos menores teores de FDN e FDA e dos maiores valores de DIVMS destes tratamentos(Tabela2). Estes resultados podem ser explicados pela capacidade do $\mathrm{NaOH}$ de romper a estrutura e solubilizar componentes da parede celular 
Tabela 4 - Escores fatoriais para os fatores que descreveram as características: qualidade nutricional (QN), maturidade fisiológica (MF) e velocidade de degradação de carboidratos fibrosos (VDF)

Table 4 - Factorial scores that describe the characteristics: nutritional quality (NQ), physiological maturity (PM), and fiber carbohydrate degradation velocity (FDV)

\begin{tabular}{|c|c|c|c|c|}
\hline $\begin{array}{l}\text { Meses } \\
\text { Months }\end{array}$ & $\begin{array}{l}\text { Tratamento } \\
\text { Treatment }\end{array}$ & $\begin{array}{l}\text { Fator } \mathrm{QN} \\
\text { Factor } N Q\end{array}$ & $\begin{array}{l}\text { Fator MF } \\
\text { Factor PM }\end{array}$ & $\begin{array}{l}\text { Fator VDF } \\
\text { Factor FDV }\end{array}$ \\
\hline \multirow{9}{*}{11} & Controle (Control) & $-1,21155$ & $-0,98921$ & 2,31102 \\
\hline & L. plantarum $1,0 \times 10^{6} \mathrm{ufc}^{1}$ & $-0,97366$ & $-0,87935$ & $-0,31075$ \\
\hline & L. plantarum $1,2 \times 10^{6} \mathrm{ufc}^{1}$ & $-0,95539$ & $-0,77072$ & 0,09520 \\
\hline & L. plantarum $1,4 \times 10^{6} \mathrm{ufc}^{1}$ & $-0,73188$ & $-0,33303$ & $-1,04379$ \\
\hline & Resíduo da colheita da soja (R.soja) & & & \\
\hline & Soy crop residue (R.soy) & 0,95624 & $-1,23524$ & 0,47363 \\
\hline & $\mathrm{NaOH}$ & $-0,65881$ & $-0,53929$ & $-1,07544$ \\
\hline & R.soja (R.soy) $+\mathrm{NaOH}$ & 1,49543 & $-1,18988$ & $-0,86137$ \\
\hline & R.soja $\left(\right.$ R.soy) + L. plantarum $1,0 \times 10^{6}$ & 1,26289 & $-1,05760$ & 0,02176 \\
\hline \multirow{9}{*}{13} & Controle (Control) & $-0,70395$ & 0,81645 & $-1,15634$ \\
\hline & L. plantarum $1,0 \times 10^{6} \mathrm{ufc}^{1}$ & $-0,64842$ & 0,51083 & $-1,05858$ \\
\hline & L. plantarum $1,2 \times 10^{6} \mathrm{ufc}^{1}$ & $-0,35051$ & 0,11831 & $-0,10084$ \\
\hline & L. plantarum $1,4 \times 10^{6} \mathrm{ufc}^{1}$ & $-0,90181$ & 1,10926 & 1,64499 \\
\hline & Resíduo da colheita da soja (R.soja) & 1,22673 & 0,40485 & 0,44194 \\
\hline & Soy crop residue (R.soy) & & & \\
\hline & $\mathrm{NaOH}$ & $-0,06341$ & 1,86823 & $-0,54168$ \\
\hline & R.soja $($ R.soy $)+\mathrm{NaOH}$ & 1,28014 & 1,18190 & 0,52997 \\
\hline & R.soja $\left(\right.$ R.soy) + L. plantarum $1,0 \times 10^{6}$ & 0,97794 & 0,98449 & 0,63028 \\
\hline
\end{tabular}

1 Unidades formadoras de colônia (colony forming units).

(Mattos, 1985). De acordo com Merchen \& Bourquin (1994), o tratamento da forragem com substâncias hidrolíticas, como o $\mathrm{NaOH}$, resulta em consideráveis alterações na estrutura e composição da parede celular, com solubilização parcial da hemicelulose, aumentando a extensão da degradação dos polissacarídeos.

A idade da cana-de-açúcar utilizada para ensilagem teve pouca influência sobre os escores fatoriais do fator QN, com pequeno aumento dos escores para a idade de 13 meses (Figura 2).

Observou-se aumento dos escores do fator MF (Tabela 4) para cada tratamento com o avançar da idade da cana-deaçúcar. Assim, esse fator seguiu comportamento geral crescente, bastante evidenciado com a mudança de sinal dos escores de uma idade para outra (Figura 2).

$\mathrm{O}$ desenvolvimento da forragem envolve a maturação com o avanço da idade fisiológica. À medida que a forragem amadurece, $\mathrm{o}$ acúmulo de carboidratos estruturais da parede celular e o processo de lignificação diminuem o seu valor nutritivo. Esse mesmo processo ocorre com a parede celular da cana-de-açúcar, no entanto, o que se observa normalmente é a melhoria na digestibilidade desta forragem com o avanço da idade fisiológica, explicada pelo elevado acúmulo de CS e, conseqüentemente, pelo aumento do valor energético representado pelo conteúdo celular (Van Soest, 1994).

De fato, quando analisados os resultados médios para as variáveis (Tabela 2) que se correlacionaram de forma positiva com o fator MF, foram observados expressivos aumentos nos teores de CS para o material ensilado quando

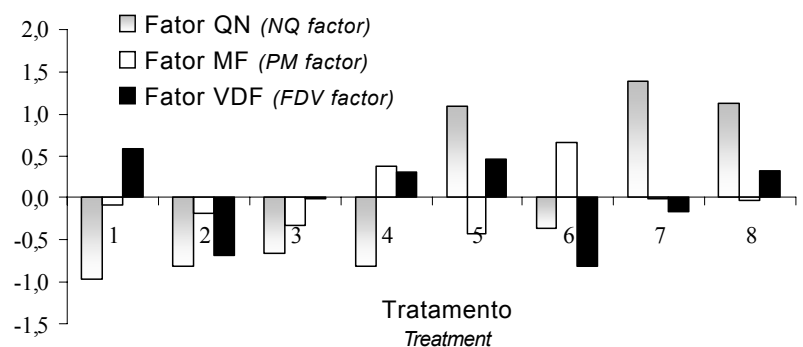

Figura 1 - Comportamento médio (escores fatoriais) dos fatores qualidade nutricional (QN), maturidade fisiológica (MF) e velocidade de degradação dos carboidratos fibrosos (VDF), na comparação entre tratamentos: 1 - controle, 2 - L. plantarum $10^{6}, 3$ - L. plantarum 1,2 $\times 10^{6}, 4-$ L. plantarum $1,4 \times 10^{6}, 5-$ resíduo, $6-\mathrm{NaOH}$, $7-$ resíduo $+\mathrm{NaOH}, 8-$ resíduo + L. plantarum $10^{6}$.

Figure 1 - Mean behavior (factorial scores) of the factors: nutritional quality (NQ), physiological maturity (PM), and fiber carbohydrate degradation velocity (FDV), among treatments: 1 - control, 2 - L. plantarum 106, 3 - L. plantarum 1,2 $210^{6}$, 4 - L. plantarum $1,4 \times 10^{6}, 5$-residue, $6-\mathrm{NaOH}, 7$-residue $+\mathrm{NaOH}, 8-$ residue + L. plantarum $10^{6}$.

a cana-de-açúcar apresentava 13 meses, em relação aos 11 meses. Também foram observados aumentos nos teores de lignina e, conseqüentemente, na fração indegradável da FDN. A lignina tem sido reconhecida como o principal componente químico afetando a digestibilidade da parede celular, cujo efeito direto tem sido explicado por hipóteses, como a do seu efeito tóxico aos microrganismos fibrolíticos, a limitação da ação das enzimas fibrolíticas criada pela hidrofobicidade resultante da deposição dos polímeros 
de lignina com a maturidade da planta e a do impedimento físico causado pela ligação polissacarídeo-lignina, limitando o acesso das enzimas (hipótese mais aceita) (Jung \& Deetz, 1993).

A fração indegradável da parede celular é muito importante, em razão da capacidade limitada de ingestão da fração da FDN pelo animal. Portanto, a produtividade animal depende de sua habilidade não só de consumir, mas também de digerir esta fração (Allen \& Mertens, 1988). Assim, a digestibilidade da FDN pode ser considerada parâmetro importante na avaliação da qualidade de forragens (Oba \& Allen, 1999). Contudo, este fator não deve ser considerado isoladamente, principalmente para cana-de-açúcar, em decorrência de seu elevado teor de CS.

Embora as silagens confeccionadas com a cana-deaçúcar colhida aos 13 meses tenham apresentado valores mais elevados da fração indegradável da FDN, a digestibilidade destas silagens foi mais alta, provavelmente como resultado dos menores teores de FDN observados nas silagens do segundo período, das menores quantidades proporcionais da fração indegradável da FDN e pelos teores de CS (em média 100\% mais altos, Tabela 2), que possuem elevada digestibilidade. Essas informações devem ser destacadas, evitando-se interpretações equivocadas quanto ao teor da fração indegradável da FDN.

Os escores fatoriais para o fator VDF apresentaram comportamento bastante variável em relação aos tratamentos (Figura 1) e leve tendência de aumento dos seus escores médios da idade de 11 para 13 meses (Figura 2), impossibilitando o estabelecimento de um padrão de comportamento para os escores fatoriais deste fator.

As maiores fontes de variação nos estudos de cinética de digestão são a espécie forrageira e o grau de maturidade.

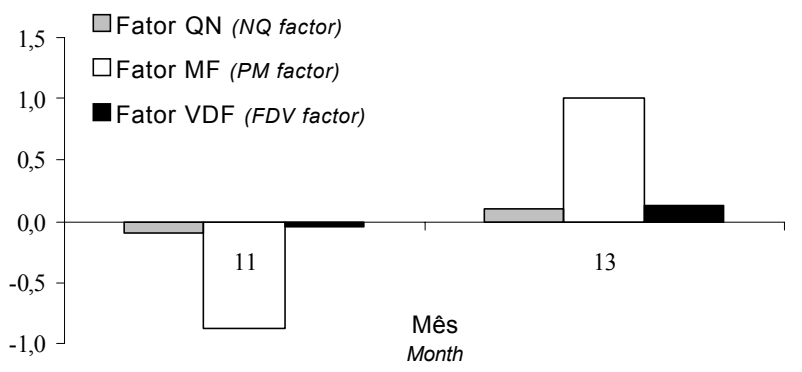

Figura 2 - Comportamento médio (escores fatoriais) dos fatores qualidade nutricional (QN), maturidade fisiológica (MF) e velocidade de degradação dos carboidratos fibrosos (VDF), de acordo com a idade da cana-deaçúcar.

Figure 2 - Mean behavior (factor scores) of the factors: nutritional quality $(N Q)$, physiological maturity $(P M)$, and fiber carbohydrate degradation velocity (FDV) according to sugar cane age.
Smith et al. (1972) observaram que, embora as leguminosas tenham maior fração indigestível da FDN, a taxa de digestão da fibra é maior que a das gramíneas $\left(0,116 \times 0,096 \mathrm{~h}^{-1}\right)$. Buxton \& Brasche (1991) observaram redução nas taxas de digestão da FDN, celulose e hemicelulose de talos de alfafa com o aumento da maturidade. Buxton (1989) observou que a taxa de digestão de talos de gramíneas maduras foi $44 \%$ da taxa observada para as plantas jovens, enquanto para leguminosas foi $66 \%$.

No entanto, Azevedo et al. (2003), avaliando a taxa de degradação da FDN de 18 variedades de cana-de-açúcar, em diferentes estádios de maturidade, não observaram variação nas taxas de 14 para 18 meses, que apresentaram médias de 0,031 e $0,030 \mathrm{~h}^{-1}$, respectivamente, sendo que as taxas de degradação da FDN das variedades observadas por esses autores variaram de 0,012 a $0,049 \mathrm{~h}^{-1}$, indicando que, provavelmente, a variação na taxa de degradação da FDN da cana-de-açúcar é mais correlacionada à variedade que ao estádio de maturidade.

Os resultados médios para as características perda de matéria seca (PMS), nitrogênio amoniacal, em porcentagem do nitrogênio total (NA), concentrações dos ácidos acético (ACE) e propiônico (PROP) e do etanol (ET) e o potencial hidrogeniônico $(\mathrm{pH})$ das silagens, de acordo com os diferentes tratamentos, são apresentados na Tabela 5 .

De forma semelhante às variáveis de composição química das silagens, foram observadas elevadas comunalidades para as característica de fermentação, com valores próximos ou superiores a $90 \%$ (Tabela 6 ).

O fator 1 correlacionou-se positivamente e de maneira mais pronunciada com as variáveis perda de MS e as concentrações dos ácidos acético (ACE) e propiônico (PROP) e de etanol (ET) (Tabela 6). Portanto, convencionou-se que este fator representaria o fator "perdas e fermentação secundária" (fator PFS).

O fator 2 apresentou elevada correlação positiva com o pH (Tabela 6), indicando que o $\mathrm{pH}$ representaria o fator "potencial hidrogeniônico" $(\mathrm{PH})$.

Quanto ao fator 3, por sua elevada correlação com a concentração de nitrogênio amoniacal das silagens (Tabela 6), foi denominado fator "degradação protéica" (DP).

Os tratamentos sem a inclusão do resíduo da colheita da soja apresentaram os escores fatoriais mais elevados do fator PFS (Tabela 7) nas duas épocas avaliadas. Quando contrastados os tratamentos entre as duas idades, observaram-se diferenças pronunciadas entre os tratamentos com adição do resíduo e os tratamentos sem resíduo, além da mudança de sinal dos escores do fator PFS (Figura 3 ). Somente o tratamento com adição do resíduo apresentou 
Tabela 5 - Resultados médios para as características perda de matéria seca (PMS), nitrogênio amoniacal (NA), concentração dos ácidos acético (ACE), propiônico (PROP) e de etanol (ET) e potencial hidrogeniônico $(\mathrm{pH})$ das silagens

Table 5 - Mean dry matter loss (DML), ammonia-N (AN), acetic acid (ACE), propionic acid (PRO), and ethanol (ET) concentration, and hydrogen potential $(\mathrm{pH})$ of silages

\begin{tabular}{|c|c|c|c|c|c|c|c|}
\hline $\begin{array}{l}\text { Meses } \\
\text { Months }\end{array}$ & $\begin{array}{c}\text { Tratamento } \\
\text { Treatment }\end{array}$ & $\begin{array}{l}\text { PMS (\%) } \\
\text { DML (\%) }\end{array}$ & $\begin{array}{l}\mathrm{NA}^{2} \\
\mathrm{AN}^{2}\end{array}$ & $\begin{array}{l}\mathrm{ACE}^{3} \\
A C E^{3}\end{array}$ & $\begin{array}{l}\mathrm{PRO}^{3} \\
P R O^{3}\end{array}$ & $\mathrm{ET}^{3}$ & $\mathrm{pH}$ \\
\hline \multirow{9}{*}{11} & Controle (Control) & 21,7 & 6,8 & 3,1 & 1,2 & 9,9 & 3,16 \\
\hline & L. plantarum $1,0 \times 10^{6} \mathrm{ufc} / \mathrm{g}^{1}$ & 27,5 & 7,0 & 2,6 & 1,1 & 15,6 & 3,16 \\
\hline & L. plantarum $1,2 \times 10^{6} \mathrm{ufc} / \mathrm{g}^{1}$ & 29,9 & 6,3 & 2,9 & 1,1 & 13,9 & 3,16 \\
\hline & L. plantarum $1,4 \times 10^{6} \mathrm{ufc} / \mathrm{g}^{1}$ & 28,0 & 7,4 & 2,9 & 1,2 & 14,2 & 3,12 \\
\hline & Resíduo da colheita da soja (R.soja) & & & & & & \\
\hline & Soy crop residue (R.soy) & 16,4 & 5,3 & 2,1 & 0,7 & 3,7 & 3,55 \\
\hline & $\mathrm{NaOH}$ & 29,9 & 7,4 & 4,5 & 1,2 & 8,4 & 3,72 \\
\hline & R.soja (R.soy) $+\mathrm{NaOH}$ & 19,0 & 4,1 & 2,1 & 0,7 & 6,0 & 3,83 \\
\hline & R.soja $($ R.soy $)+L$. plantarum $1,0 \times 10^{6}$ & 16,7 & 5,1 & 1,8 & 0,7 & 6,0 & 3,50 \\
\hline \multirow{10}{*}{13} & Controle (Control) & 28,7 & 9,6 & 3,8 & 1,0 & 15,9 & 3,59 \\
\hline & L. plantarum $1,0 \times 10^{6} \mathrm{ufc} / \mathrm{g}^{1}$ & 30,6 & 9,2 & 5,5 & 1,4 & 18,2 & 3,58 \\
\hline & L. plantarum $1,2 \times 10^{6} \mathrm{ufc} / \mathrm{g}^{1}$ & 25,5 & 11,5 & 3,3 & 1,0 & 14,1 & 3,52 \\
\hline & L. plantarum $1,4 \times 10^{6} \mathrm{ufc} / \mathrm{g}^{1}$ & 25,9 & 8,8 & 3,4 & 1,1 & 14,4 & 3,45 \\
\hline & Resíduo da colheita da soja (R.soja) & & & & & & \\
\hline & Soy crop residue (R.soy) & 12,1 & 4,5 & 2,0 & 0,5 & 3,5 & 3,82 \\
\hline & $\mathrm{NaOH}$ & 22,9 & 13,1 & 4,2 & 0,9 & 10,3 & 3,83 \\
\hline & R.soja (R.soy) $+\mathrm{NaOH}$ & 11,9 & 3,9 & 2,3 & 0,4 & 3,7 & 3,96 \\
\hline & R.soja $($ R.soy $)+L$. plantarum $1,0 \times 10^{6}$ & 14,2 & 5,2 & 2,7 & 0,7 & 4,6 & 3,82 \\
\hline & $\mathrm{CV}(\%)$ & 11,23 & 8,43 & 10,59 & 11,87 & 14,49 & 2,09 \\
\hline
\end{tabular}

\footnotetext{
1 Unidades formadoras de colônia por grama de matéria natural (colony forming units per gram of natural matter).

2 Porcentagem do nitrogênio total (percentage of total nitrogen).

$3 \%$ da MS (\% of DM).
}

superioridade para o fator PFS, podendo ser observadas menores perdas de MS e mais baixas concentrações dos ácidos acético e propiônico e de etanol (Tabela 5).

De acordo com McDonald et al. (1991), silagens bem preservadas devem apresentar perdas de MS por oxidação e por fermentação entre 2 e $4 \%$, mas citam uma média de $19,4 \%$ de perdas totais de MS observadas na literatura. As perdas de MS das silagens neste experimento atingiram valores bastante elevados, de até $30,6 \%$ de MS para o tratamento com inoculante microbiano. Pedroso (2003), avaliando a dinâmica da produção de etanol e das perdas durante a ensilagem da cana-de-açúcar sem aditivos, constatou correlação positiva entre o teor de etanol e as perdas de MS total e na forma de gases ( $\mathrm{r}=0,893$ e 0,903, respectivamente) e correlação negativa entre o teor de etanol e o teor de CS residuais na silagem $(r=-0,863)$, corroborando a afirmação de McDonald et al. (1991) de que a produção de etanol é acompanhada de acentuada perda de MS dos substratos na forma de $\mathrm{CO}_{2}$ e $\mathrm{H}_{2} \mathrm{O}$.

De fato, neste experimento, observou-se (Tabela 5) que o aumento nas concentrações de etanol nas silagens foi acompanhado de proporcional aumento nas perdas de MS. O comportamento geral da silagem tratada com $\mathrm{NaOH}$, no entanto, apesar da menor concentração de etanol, apresentou elevada perda de MS. Entretanto, nestas silagens foi observada maior concentração do ácido acético, que, em sua via de fermentação, promove produção de uma molécula de
$\mathrm{CO}_{2}$ para cada molécula de acetato produzido, aumentando, conseqüentemente, a perda de MS.

As perdas de MS e o teor de etanol das silagens controle e dos tratamentos com inoculante microbiano foram semelhantes aos observados por Kung Jr. \& Stanley (1982), que obtiveram valores de $29 \%$ de perdas de MS e teor de etanol de $13,7 \%$, para cana-de-açúcar ensilada aos 15 meses de crescimento e conservada durante 60 dias.

O maior escore fatorial (fator PFS) da silagem inoculada com L. plantarum, quando contrastado com as demais silagens (Figura 3 ), está associado principalmente às maiores perdas de MS e à produção de etanol. Higginbothan et al. (1998), avaliando a aplicação de inoculante contendo L. plantarum $\left(1,5 \times 10^{4} \mathrm{ufc} / \mathrm{t} \mathrm{MN}\right)$ e $P$. cerevisae $\left(3 \times 10^{5} \mathrm{ufc} / \mathrm{g}\right)$ em silagem de milho, constataram que a silagem inoculada apresentou teor de etanol duas vezes superior ao da controle. Pedroso (2003), estudando a influência de aditivos na ensilagem de cana-de-açúcar, observou que a silagem tratada com o inoculante contendo L. plantarum $\left(1 \times 10^{6} \mathrm{ufc} / \mathrm{g}\right)$ apresentou maior perda de MS e concentração de etanol em relação aos outros tratamentos.

Estes resultados sugerem que a adição de inoculante contendo L. plantarum não é capaz de controlar o desenvolvimento das leveduras, confirmando a informação de McDonald et al. (1991) de que apenas o declínio do pH não é suficiente para impedir o desenvolvimento destes microrganismos. Também estão de acordo com os dados 
Tabela 6 - Cargas fatoriais, comunalidade de cada variável e porcentagem da variância total, correspondente a cada fator, após a rotação pelo método "Varimax", na análise fatorial

Table 6 - Rotated factor pattern, communality, and total variance percentage, corresponding to each factor, after rotation by the factorial analysis "Varimax" method

\begin{tabular}{|c|c|c|c|c|}
\hline \multirow[t]{2}{*}{$\begin{array}{l}\text { Variável } \\
\text { Item }\end{array}$} & \multicolumn{3}{|c|}{$\begin{array}{c}\text { Carga fatorial } \\
\text { Rotated factor pattern }\end{array}$} & \multirow[t]{2}{*}{$\begin{array}{c}\text { Comunalidade (\%) } \\
\text { Communality (\%) }\end{array}$} \\
\hline & $\begin{array}{l}\text { Fator } 1 \\
\text { Factor } 1\end{array}$ & $\begin{array}{l}\text { Fator } 2 \\
\text { Factor } 2\end{array}$ & $\begin{array}{l}\text { Fator } 3 \\
\text { Factor } 3\end{array}$ & \\
\hline Perda de MS (DM loss) & 0,73380 & $-0,54525$ & 0,32709 & 94,27 \\
\hline Nitrogênio amoniacal (Ammonia-N) & 0,37098 & $-0,07615$ & 0,91745 & 98,51 \\
\hline $\mathrm{ACE}$ & 0,89313 & 0,08182 & 0,41322 & 97,51 \\
\hline $\mathrm{PH}$ & 0,06909 & 0,98296 & $-0,00716$ & 97,10 \\
\hline $\begin{array}{l}\% \text { da variância explicada pelos fatores } \\
\% \text { of variance explained by the factors }\end{array}$ & 69,97 & 19,36 & 6,20 & 95,54 \\
\hline
\end{tabular}

Tabela 7 - Escores fatoriais para os fatores que descreveram as características perdas e fermentação secundária (PFS), potencial hidrogeniônico $(\mathrm{PH})$ e degradação protéica (DP)

Table 7 - Factorial scores that describe the characteristics: "losses and secondary fermentation" (LSF), "hydrogen potential" (PH), and "protein degradation" (PD)

\begin{tabular}{|c|c|c|c|c|}
\hline Meses & Tratamento & Fator PFS & Fator $\mathrm{pH}$ & Fator DP \\
\hline Months & Treatment & Factor LSF & Factor $\mathrm{pH}$ & Factor PD \\
\hline \multirow[t]{9}{*}{11} & Controle (Control) & 0,00199 & $-1,01951$ & $-0,48528$ \\
\hline & L. plantarum $1,0 \times 10^{6} \mathrm{ufc}^{1}$ & $-0,27944$ & $-1,59122$ & $-0,01689$ \\
\hline & L. plantarum $1,2 \times 10^{6} \mathrm{ufc}^{1}$ & 0,25500 & $-1,43229$ & $-0,54996$ \\
\hline & L. plantarum $1,4 \times 10^{6} \mathrm{ufc}^{1}$ & 0,03270 & $-1,56287$ & $-0,07951$ \\
\hline & Resíduo da colheita da soja (R.soja) & & & \\
\hline & Soy crop residue (R.soy) & $-0,89358$ & 0,12019 & $-0,57695$ \\
\hline & $\mathrm{NaOH}$ & 2,06620 & 0,80333 & $-0,89505$ \\
\hline & R.soja (R.soy) $+\mathrm{NaOH}$ & $-0,25468$ & 0,64814 & $-1,04284$ \\
\hline & R.soja (R.soy) + L. plantarum $1,0 \times 10^{6}$ & $-1,25716$ & $-0,24513$ & $-0,37278$ \\
\hline \multirow[t]{9}{*}{13} & Controle (Control) & 0,54301 & 0,00590 & 0,93912 \\
\hline & L. plantarum $1,0 \times 10^{6} \mathrm{ufc}^{1}$ & 2,40319 & 0,33387 & 0,02208 \\
\hline & L. plantarum $1,2 \times 10^{6} \mathrm{ufc}^{1}$ & 0,47988 & $-0,23323$ & 1,90345 \\
\hline & L. plantarum $1,4 \times 10^{6} \mathrm{ufc}^{1}$ & 0,15849 & $-0,43738$ & 0,61727 \\
\hline & Resíduo da colheita da soja (R.soja) & $-1,08693$ & 0,95316 & $-0,52046$ \\
\hline & Soy crop residue (R.soy) & & & \\
\hline & $\mathrm{NaOH}$ & $-0,14462$ & 1,21484 & 2,43249 \\
\hline & R.soja $($ R.soy) $+\mathrm{NaOH}$ & $-0,68797$ & 1,40945 & $-0,82383$ \\
\hline & R.soja (R.soy) + L. plantarum $1,0 \times 10^{6}$ & $-0,37630$ & 1,03273 & $-0,58464$ \\
\hline
\end{tabular}

${ }^{1}$ Unidades formadoras de colônia por grama de matéria natural (colony forming units per gram of natural matter).

obtidos em outros trabalhos, nos quais a aplicação de inoculantes contendo L. plantarum foi incapaz de reduzir a população de leveduras em silagens (Bolsen et al., 1992; Ranjit \& Kung Jr., 2000).

Observou-se aumento dos escores fatoriais do fator $\mathrm{pH}$ (Tabela 7) para cada tratamento com o aumento do ciclo de desenvolvimento da cana-de-açúcar utilizada para ensilagem. Este aumento dos escores do fator $\mathrm{pH}$ de uma idade para outra é ilustrado na Figura 4.

Avaliando as médias dos escores fatoriais dos tratamentos entre as duas idades (Figura 3), obtiveram-se escores negativos, com redução dos escores fatoriais e aumento gradativo das doses do inoculante microbiano, e escores positivos para os tratamentos com resíduo e com $\mathrm{NaOH}$, indicando acréscimo no $\mathrm{pH}$ final destas silagens.
Geralmente, somente o baixo $\mathrm{pH}$ final não garante que a atividade dos microrganismos indesejáveis, como os clostridias e as enterobactérias, seja prevenida durante o processo de fermentação. Para que isso ocorra, é necessário que a redução do $\mathrm{pH}$ seja rapidamente atingida. Quando se trabalha com forragens com altos teores de açúcares e baixos de proteína, ocorre normalmente a estabilidade do pH antes do décimo dia de ensilagem (McDonald et al., 1991). Em silagens de cana-de-açúcar, o pH atingiu valores inferiores a 4,0 no terceiro dia de ensilagem, conforme observado por Pedroso (2003).

Mesmo no tratamento com a combinação do resíduo com o $\mathrm{NaOH}$, no qual foi observado o maior escore fatorial para o fator $\mathrm{pH}$ (Figura 3), esse tratamento resultou em silagem com $\mathrm{pH}$ dentro de um patamar adequado à conservação 


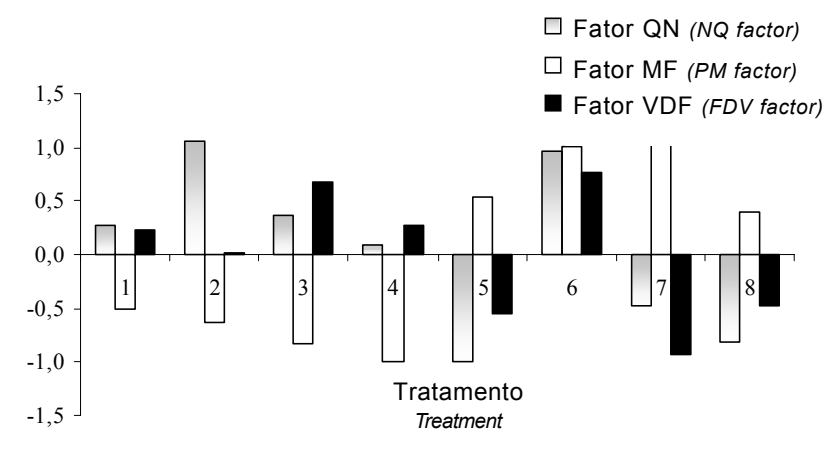

Figura 3 - Comportamento médio (escores fatoriais) dos fatores: "perdas e fermentação secundária" (PFS), "potencial hidrogeniônico" (PH) e "degradação protéica" (DP), quando comparados os tratamentos 1 - controle, 2 - L. plantarum $10^{6}, 3$ - L. plantarum $1,2 \times 10^{6}$, 4 - L. plantarum $1,4 \times 10^{6}, 5-$ resíduo, $6-\mathrm{NaOH}$, 7 - resíduo $+\mathrm{NaOH}, 8-$ resíduo + L. plantarum $10^{6}$.

Figure 3 - Mean behavior (factor scores) of the factors: "losses and secondary fermentation" (LSF), "hydrogen potential" $(P H)$, and "protein degradation" (PD) among treatments: 1 - control, 2 - L. plantarum $10^{6}, 3$ - L. plantarum $1,2 \times 10^{6}, 4$ - L. plantarum $1,4 \times 10^{6}, 5$-residue, $6-\mathrm{NaOH}, 7-$ residue $+\mathrm{NaOH}, 8$-residue + L. plantarum $10^{6}$

(Tabela 5), uma vez que, de acordo com McDonald etal.(1991), silagens de boa qualidade podem apresentar $\mathrm{pH}$ de 3,6 a 4,2.

Quanto ao fator DP, observaram-se escores fatoriais mais baixos para os tratamentos com adição do resíduo (Tabela 7; Figura 3). Esse comportamento refletiu os menores teores de nitrogênio amoniacal verificados para estas silagens (Tabela 5). Quando comparadas as duas idades, foi observado aumento pronunciado, de 11 para 13 meses, dos escores fatoriais para o fator DP (Figura 4).

Esses escores fatoriais (fator DP) mais elevados para cana ensilada aos 13 meses podem estar relacionados ao princípio da preservação da forragem na forma de silagem, que se baseia no processo de conservação em ácido, em que o decréscimo do pH ocasiona redução da atividade proteolítica, mediada por enzimas da própria planta (Muck \& Bolsen, 1991), uma vez que os escores fatoriais (fator PH) também foram bem superiores para cana ensilada aos 13 meses. No entanto, os valores de nitrogênio amoniacal verificados para as silagens de cana-de-açúcar ensilada aos 11 meses estiveram todos abaixo de $10 \%$ e, para cana ensilada aos 13 meses, abaixo de $15 \%$, indicando que o processo de fermentação não resultou em quebra excessiva da proteína em amônia e que os aminoácidos constituem a maior parte do nitrogênio não-protéico (Van Soest, 1994). De acordo com Mahanna (1993), para obtenção de silagens estáveis de gramíneas ou leguminosas, o teor de nitrogênio amoniacal deve situar-se abaixo de $15 \%$.

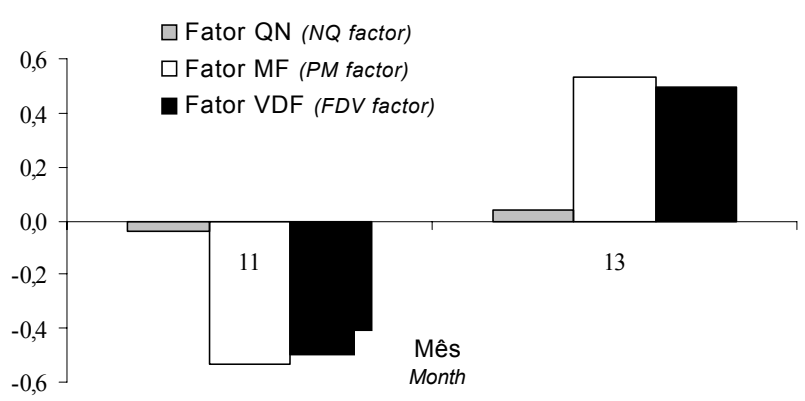

Figura 4 - Comportamento médio (escores fatoriais) dos fatores "perdas e fermentação secundária" (PFS), "potencial hidrogeniônico" ( $\mathrm{pH}$ ) e "degradação protéica" (DP), de acordo com a idade da cana-de-açúcar.

Figura 4 - Mean behavior (factorial scores) of the factors: "losses and secondary fermentation" (LSF), "hydrogen potential" ( $(\mathrm{pH})$, and "protein degradation" (PD) according to sugar cane age.

\section{Conclusões}

A adição do resíduo da colheita da soja à cana-de-açúcar melhorou a qualidade nutritiva e reduziu as perdas de matéria seca e a produção de etanol das silagens.

O tratamento das silagens com hidróxido de sódio reduziu a produção de etanol, mas diminuiu as perdas de matéria seca das silagens.

Da mesma forma, o inoculante microbiano contendo L. plantarum não melhorou a qualidade nutritiva da silagem nem reduziu as perdas de matéria seca e a produção de etanol.

\section{Literatura Citada}

ALCÂNTARA, E.; AGUILERA, A.; ELLIOT R. et al. Fermentation and utilization by lambs of sugarcane harvested fresh and ensiled with and without $\mathrm{NaOH}$. 4. Ruminal Kinetics Animal Feed Science and Technology, v.23, p.323-331, 1989.

ALLEN, M.S.; MERTENS, D.R. Evaluating constraints on fiber digestion by rumen microbes. Journal of Nutrition, v.118, p.261-270, 1988 .

ALLI, I.; BAKER, B.E. Studies on the fermentation of chopped sugarcane. Animal Feed Science and Technology, v.7, p.411417, 1982 .

ALLI, I.; FAIRBAIRN, R.; BAKER, B.E. The effects of ammonia on the fermentation of chopped sugarcane. Animal Feed Science and Technology, v.9, p.291-299, 1983.

ANDRADE, J.B.; JÚNIOR, E.F.; BRAUN, G. Valor nutritivo da silagem de cana-de-açúcar tratada com uréia e acrescida de rolãode-milho. Pesquisa Agropecuária Brasileira, v.36, n.9, p.1169-1174, 2001

ASSOCIATION OF OFFICIAL ANALYTICAL CHEMISTS - AOAC. Official methods of analysis. 15.ed. Arlington: 1990. 1117p.

AZEVÊDO, J.A.G.; PEREIRA, J.C.; CARNEIRO, P.C.S. et al. Avaliação da divergência nutricional de variedades de cana-deaçúcar (Saccharum spp.). Revista Brasileira de Zootecnia v.32, n.6, p.1431-1442, 2003. 
BOLSEN, K.K.; LIN, C.; BRENT, B.E. et al. Effect of silage additives on the microbial succession and fermentation process of alfalfa and corn silages. Journal of Dairy Science, v.75, n.11, p.3066-3083, 1992.

BUXTON, D.R.; BRASCHE, M.R. Digestibility of structural carbohydrates in cool-season grass and legume forages. Crop Science, v.31, p.1338-1345, 1991 .

BUXTON, D.R. In vitro digestion kinetics of temperate perennial forage legume and grass stems. Crop Science, v.29, p.213-219, 1989.

CARVALHO, G.J. Avaliação do potencial forrageiro e industrial de variedades de cana-de-açúcar (ciclo de ano) em diferentes épocas de corte. Lavras: Universidade Federal de Lavras, 1992. 63p. Dissertação (Mestrado em Fitotecnia) Universidade Federal de Lavras, 1992.

COAN, R.M.; SILVEIRA, R.N.; BERNARDES, T.F. et al. Composição química da cana-de-açúcar crua ou queimada ensilada com aditivo. In: REUNIÃO ANUAL DA SOCIEDADE BRASILEIRA DE ZOOTECNIA, 39., 2002, Recife. Anais... Pernambuco: Sociedade Brasileira de Zootecnia, 2002. CD-ROM.

HIGGINBOTHAM, G.E.; MUELLER, S.C.; BOLSEN, K.K. et al. Effects of inoculants containing propionic acid bacteria on fermentation and aerobic stability of corn silage. Journal of Dairy Science, v.25, p.2185-2192, 1998.

JOHNSON, R.A.; WICHERN, D.W. Applied multivariate statistical analysis. 4.ed. New Jersey: Prentice-Hall, 1998. 816p.

JUNG, H.G.; DEETZ, D.A. Cell wall lignification and degradability. In: JUNG, H.G.; BUXTON, D.R.; HATFIELD, R.D. et al. (Eds) Forage cell wall structure and digestibility. Madison: USDA, 1993. P.315-346

KUNG Jr., L.; STANLEY, R.W. Effect of stage of maturity on the nutritive value of whole-plant sugarcane preserved as silage. Journal of Animal Science, v.54, p.689-696, 1982.

LICITRA, G.; HERNANDEZ, T.M.; VAN SOEST, P.J. Standardization of procedures for nitrogen fractionation of ruminant feeds. Animal Feed Science and Technology, v.57, n. 4, p. 347-358, 1996.

McDONALD, P.; HENDERSON, A.R.; HERON, S.J.E. The biochemistry of silage. 2.ed. Marlow: Chalcomb Publication, 1991. 340p.

McDOUGALL, E.I. Studies on ruminal saliva. 1. The composition and output of sheep's saliva. Biochemical Journal, v.43, n.1, p.99-109, 1949.

MAHANNA, B. Troubleshooting silage problems. In: STATE APPLIED NUTRITION CONFERENCE, 4., 1993, Wisconsin. Proceedings... Wisconsin, 1993. p.1-21.

MATSUOKA, S.; HOFFMANN, H.P. Variedades de cana-de-açúcar para bovinos. In: SIMPÓSIO SOBRE NUTRIÇÃO DE BOVINOS, 5., 1993, Piracicaba. Anais... São Paulo: Fundação de Estudos Agrários Luiz de Queiroz, 1993. p.17-35.

MATTOS, W.R.S. Utilização de bagaço de cana-de-açúcar na alimentação de ruminantes. In: PEIXOTO, A.M.; MOURA, J.C.; FARIA, V.P. (Eds.) Utilização de resíduos agro-industriais da cana-de-açúcar na alimentação de ruminantes. Piracicaba: Fundação de Estudos Agrários Luiz de Queiroz, 1985. 72p.

MAURÍCIO, R.M.; MOULD, F.L.; DHANOA, M.S. et al. A semiautomated in vitro gas production technique for ruminant feedstuff evaluation. Animal Feed Science and Technology, v.79, p.321-330, 1999.

MERCHEN, N.R.; BOURQUIN, L.D. Processes of digestion and factors influencing digestion of forage-based diets by ruminants. In: FAHEY JR., G.C. (Ed.). Forage quality, evaluation and utilization. Madison: American Society of Agronomy, 1994. p.564-612.

MUCK, R.E.; BOLSEN, K.K. Silage preservation and additive products. In: MUCK, R.E.; BOLSEN, K.K. (Eds.) Field guide and silage management in North America. West Des Moines: National Feed Ingredients Association, 1991. p.105-126.

NEUMANN, M.; RESTLE, J.; ALVES FILHO, D.C. et al. Avaliação do valor nutritivo da planta e da silagem de diferentes híbridos de sorgo (Sorghum bicolor, L. Moench). Revista Brasileira de Zootecnia, v.31, n.1, p.293-301, 2002 (supl.)

NUSSIO, L.G.; SCHIMDT, P.; PEDROSO, A.F. Silagem de cana-deaçúcar. In:SIMPÓSIO DE FORRAGICULTURA E PASTAGENS: TEMAS EM EVIDÊNCIA - SUSTENTABILIDADE, 2003 , Lavras. Anais... Lavras: Universidade Federal de Lavras, 2003. p. 49-74.

OBA, M.; ALLEN, M.S. Evaluation of the importance of the digestibility of neutral detergent fiber from forage: effects on dry matter intake and milk yield of dairy cows. Journal of Dairy Science, v.82, n.3, p.589-596, 1999

PEDROSO, A.F. Aditivos químicos e microbianos no controle de perdas e na qualidade de silagem de cana-de-açúcar (Saccharum officinarum L.). Piracicaba: Escola Superior de Agricultura "Luiz de Queiroz", 2003. 120p. Dissertação (Doutorado em Agronomia) - Escola Superior de Agricultura "Luiz de Queiroz", 2003.

PELL, A.N.; SCHOFIELD, P. Computerized monitoring of gas production to measure forage digestion in vitro. Journal of Dairy Science, v.76, n.9, p.1063-1073, 1993.

PESCE, D.M.C.; GONÇALVES, L.C.; RODRIGUEZ, N.M Porcentagem, perda e digestibilidade in vitro da matéria seca das silagens de 20 genótipos de sorgo. Arquivo Brasileiro de Medicina Veterinária e Zootecnia, v.52, n.3, p.250-255, 2000 .

RANJIT, N.K.; KUNG JR., L. The effect of Lactobacillus buchneri, Lactobacillus plantarum, or a chemical preservative on the fermentation and aerobic stability of corn silage. Journal of Dairy Science, v.83, p.526-535, 2000.

RODRIGUES, A.A.; CRUZ, G.M.; BATISTA, L.A.R. et al. Qualidade de dezoito variedades de cana-de-açúcar como alimento para bovinos. In: REUNIÃO ANUAL DA SOCIEDADE BRASILEIRA DE ZOOTECNIA, 38., 2001, Piracicaba. Anais... São Paulo: Sociedade Brasileira de Zootecnia, 2001a. CD-ROM.

RODRIGUES, P.H.M.; ALMEIDA, T.F.; MELOTTI, L. et al. Efeitos da adição de inoculantes microbianos sobre a composição bromatológica e sobre a fermentação da silagem de girassol produzida em silos experimentais. Revista Brasileira de Zootecnia, v.30, n.6, p.2169-2175, 2001b. (suplemento)

RODRIGUES, P.H.M.; RUZANTE, J.M.; SENATORE, A.L. et al. Avaliação do uso de inoculantes microbianos sobre a qualidade fermentativa e nutricional da silagem de milho. Revista Brasileira de Zootecnia, v.33, n.3, p.538-545, 2004.

ROTZ, C.A.; MUCK, R.E. Changes in forage quality during harves and storage. In: FAHEY JR., G.C. (Ed.). Forage quality, evaluation and utilization. Madison: American Society of Agronomy, 1994. p.828-868.

SILVA, D.J.; QUEIROZ, A.C. Análise de alimentos: métodos químicos e biológicos. Viçosa, MG: Universidade Federal de Viçosa, 2002. 65p.

SILVA, S.A.R. Avaliação da eficiência fermentativa da canade-açúcar ensilada com diferentes aditivos. Goiânia: Universidade Federal de Goiás, 2003. 44p. Dissertação (Mestrado em Zootecnia) - Universidade Federal de Goiás, 2003.

SMITH, L.W.; GOERING, H.K.; GORDON, C.H. Relationships of forage compositions with rates of cell wall digestion and indigestibility of cell walls. Journal of Dairy Science, v. 55 , p. 1140-1147, 1972

VALVASORI, E.; LUCCI, C.S.; ARCARO, J.R.P. et al. Avaliação da cana-de-açúcar em substituição à silagem de milho para vacas leiteiras. Brazilian Journal of Veterinary Research and Animal Science, v.32, n.4, p.224-228, 1995.

Van SOEST, P.J. Nutritional ecology of the ruminant. 2.ed. New York: Cornell University Press, 1994. 476p.

Recebido: 04/04/05 Aprovado: 19/08/05 